Carmen Alemany Bay:

Profesora titular de Literatura hispanoamericana de la Universidad de Alicante y directora del Centro de Estudios Iberoamericanos Mario Benedetti de la citada Universidad. Ha sido antóloga y editora de obras de Miguel Hernández, entre ellas, la Obra completa. Es autora de los libros Poética coloquial hispanoamericana, El meridiano intelectual en Hispanoamérica, Mario Benedetti y Residencia en la poesía: poetas latinoamericanos de siglo $X X$. Ha publicado numerosos artículos sobre literatura latinoamericana del siglo XX y es editora de varios números monográficos.
Véase, Mario Vargas Llosa, La utopía arcaica. José María Arguedas y las ficciones del indigenismo, México, FCE, 1997.

No en los mismos términos pero sí en la misma idea incidía Giuseppe Bellini unos años antes en el artículo «Función del símbolo en Los ríos profundos de J.M ${ }^{a}$. Arguedas»: "Ernesto, como José María Arguedas, no se en cuentra a gusto en el presente, vive continuamente del pasado y anhela regresar a él, como si el pasado fuera una entraña maternal y en ella consistiera la vida verdadera. Es lo que irá continuamente insidiando al narrador, hasta llevarlo a la decisión de suicidarse», en José Carlos Rovira (editor), José María Arguedas. Indigenismo y cuestión cultural como crisis contemporánea hispanoame ricana, Barcelona, Anthropos, 1992, pp. 53-54.

2

Juan Larco (compilador), Recopilación de textos sobre José María Arguedas, Serie Valoración múltiple, La Habana, Casa de las Américas, 1976, p. 157.

3

José Carlos Rovira (presentación y selección de textos), José María Arguedas. Una recuperación indigenista del mundo peruano. Suplementos, Barcelona Anthropos, 1992, p. 41

Singularidades de José María Arguedas como escritor

CARMEN ALEMANY BAY

\title{
SINGULARIDADES DE JOSÉ MARÍA ARGUEDAS COMO ESCRITOR
}

\author{
CARMEN ALEMANY BAY \\ Universidad de Alicante-España
}

Los críticos dedicados a la obra de José María Arguedas (1911-1969) han resaltado su originalidad como narrador y coinciden en que ésta nace, en parte, de la forma cómo el escritor peruano analizó desde adentro el mundo andino. Un universo que en no pocas ocasiones aparece articulado a través de dualidades que atañen tanto a aspectos individuales como sociales: blanco / indio, español / quechua, mundo de la niñez / mundo adulto, nación peruana / capitalismo, costa / sierra, el bien / el mal, etc. Sin embargo, su obra significa algo más, y esa significación creemos que viene determinada por una serie de singularidades que van más allá de su obra literaria, pero que sin duda inciden en ella: la fusión entre su vida y su obra, su formación literaria, la inclusión de la antropología y la etnología en sus ficciones, la búsqueda de un lenguaje singular y cómo cada uno de estos aspectos contribuyen a la creación de un universo narrativo único. En definitiva, la construcción de un mundo original donde algunos, sobre todo Mario Vargas Llosa, han querido ver a un escritor en busca de una utopía arcaica ${ }^{\text {. }}$

Desde la posición de escritor poco convencional y desde la convicción de que era «un narrador más intuitivo que erudito», quiso reivindicar la cultura quechua en sus ficciones; pero con el paso de los años intuyó que, si bien ésta debía tener un papel preponderante, no debía obviarse la importancia que la cultura española había tenido en la formación idiosincrásica de su país. Como él mismo afirmó: «una integración entre ambos mundos que en la realidad histórica no se ha realizado y acaso no culmine jamás»². Pero al menos el intento debía realizarse, porque de no ser así se podía llegar a la aculturación, y ya dejó bien claro el escritor en su discurso de entrega del Premio Inca Garcilaso de la Vega cual era su posición: «Yo no soy un aculturado; yo soy un peruano que orgullosamente, como un demonio feliz, habla en cristiano y en indio, en español y en quechua ${ }^{3}$.

Un total de seis novelas y una veintena de relatos componen la obra narrativa de José María Arguedas: la primera publicación en libro fueron los cuentos de Agua (1935), y su primera novela fue editada en 1941, Yawar Fiesta. En la década de los cincuenta verían la luz Diamantes y pedernales (1954) y su mejor narración, Los ríos profundos (1958). En los años sesenta publicó El sexto (1961), Todas las sangres (1964) y Amor mundo y todos los cuentos (1967); en 1971 conoceríamos su obra póstuma, El zorro de arriba y el zorro de aba$j o$, novela inconclusa.

\section{Una obra entre la literatura y la vida}

A José María Arguedas le gustaba contarse y ficcionalizar sobre su propia experiencia: recorrer su trayectoria narrativa supone también ir visualizando sus pulsaciones vitales, y precisamente éste es otro nivel de atracción que emanan sus escritos.

Nacido el 18 de enero de 1911 en Andahuaylas, en el departamento de Apurímac, fue hijo del abogado Víctor Manuel Arguedas y de Victoria Altamirano, fallecida cuando el autor contaba con tres años. Poco tiempo después, el padre contrajo segundas nupcias con Grimanesa Arangoitia, viuda de Pacheco, quien aportó al matrimonio tres hijos. Con la madrastra y el hermanastro tendrá 
una relación tormentosa de maltratos físicos y psicológicos que marcarán el resto de su vida y que serán recordados en más de una ocasión en sus novelas y relatos. Elocuentes a este respecto son las palabras que José María Arguedas pronunció en su «Intervención en Arequipa»: «Voy a hacerles una confesión un poco curiosa: yo soy hechura de mi madastra [...] Mi niñez pasó quemada entre el fuego y el amor [...] Pero no solamente he sido hechura de mi madastra, hubo otro modelador tan eficaz como ella, un poco más bruto: $\mathrm{mi}$ hermanastro» 4 .

Desde Agua hasta El zorro de arriba y el zorro de abajo conocemos una biografía entrelazada con la literatura en la que nos va relatando su infancia en una cocina india, la intransigencia de su madrastra, los viajes con su padre por la sierra peruana, el ingreso en el colegio de Abancay o sus experiencias en Viseca y Puquio. Después vendrán otras vivencias que no siempre formarán parte de sus obras, como su estancia en Lima para estudiar en la Universidad de San Marcos, su ingreso en la cárcel, sus primeras nupcias con Celia Bustamante Bernal y las segundas con Sybila Arredondo, su trabajo como antropólogo y finalmente su obsesión por el suicidio ${ }^{5}$.

La hacienda de Viseca descrita en los cuentos de Agua, ciudades como Puquio en Yawar Fiesta, Abancay y los pueblos de la sierra peruana en Los ríos profundos, Lima en El Sexto o el puerto de Chimbote en El zorro de arriba $y$ el zorro de abajo conformarán sus espacios ficcionales que no son más que el resultado de lo vivido. Pero si los espacios estaban determinados y fijados por su conocimiento vital, no menos desconocidos serán para el lector que haya indagado en la vida de Arguedas los personajes que aparecen y reaparecen en sus ficciones. El escritor peruano proyectó el niño que fue en Ernesto, personaje principal de algunos cuentos de Agua (el que da nombre al libro y el titulado "Warma kuyay»), y también el protagonista de la novela Los ríos profundos. Otros yo del autor se harán tangibles en el personaje de Juan, del cuento «Los escoleros» (Agua); o en Santiago, el motor de la acción de los relatos de Amor mundo. Todos ellos, al igual que el autor, son hijos de un misti y han sido criados por los sirvientes, como también el niño anónimo que aparece en «Doña Cayetana», los personajes innominados de «Orovilca» o «La muerte de los Arango»; ejemplos en los que el autor se va implicando -a través de otros nombres- en una misma realidad.

Un autobiografismo más directo y menos ficcional se hará presente en El Sexto, obra en la que, como ya reseñamos, nos cuenta la experiencia vivida en una de las cárceles más agresivas del país; aunque el autobiografismo más puro lo reservará para su última novela. En ella Arguedas va barajando la realidad de la costa con sus diarios para relatarnos con detalle la agonía de sus últimos años, su voluntad de suicidarse -que empezaría a aflorar en 1966- y la imposibilidad de seguir escribiendo. La novela va creciendo a medida que su espíritu se va consumiendo hasta lograr poner el punto final a su vida; sin duda, su trágica muerte será el capítulo final de $E l$ zorro de arriba y el zorro de abajo.

La múltiple personalidad de Arguedas, sus inquietudes más íntimas, quedarán plasmadas en los nombres ficcionalizados que hemos citado; pero también recordará, para conformar un cuadro más complejo, a otros personajes que fueron decisivos en su vida. Don Felipe Maywa y don Víctor Pusa serán mencionados en Los ríos profundos con el fin de homenajear los valores humanos que le trasmitieron durante su estancia en Viseca y en Utek. También será recordado, pero desde la amargura en este caso, la experiencia traumática que vivió con su hermanastro Pablo Pacheco y que relatará en el cuento «El horno viejo» de Amor mundo: en el citado relato el protagonista es obligado por un misti a acompañarlo en un intento de seducción. Esta misma vivencia, pero con sutiles matices, ya había sido recreada en uno de sus primeros cuentos, específicamente en «Warma kuyay», y repetida en otro perteneciente a Amor mundo, «Don Antonio».

Los ejemplos señalados aquí son los más significativos que podemos encontrar en un rastreo por las ficciones arguedianas, pero a cada paso el lector puede hallar múltiples referencias personales, y hasta podría resultar ocioso la recopilación de todo el anecdotario vivencial que encontramos en los escritos de este autor. Con todo ello, cualquier acercamiento a su obra debe tener muy presente la no disociación entre vida y ficción, pero también no se debe olvidar que el suyo fue un caso extremo; como nos declara en $E l$ zorro de arriba y el zorro de abajo, vivió para la literatura y para su creación. Cuando sus temas se fueron agotando y la imposibilidad

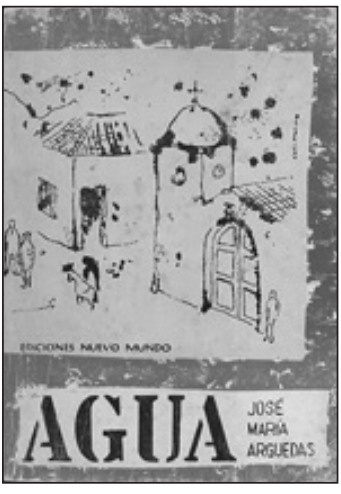

4

José María Arguedas, «Intervención en Arequipa», en Primer Encuentro de Narradores Peruanos. Arequipa 1965, Lima Casa de la Cultura, 1969. Tomamos la referencia de Rovira, José María Arguedas, op. cit., p. 9.

5

Una cronología de la vida de José María Arguedas puede consultarse en Carmen Alemany Bay, "Cronología de José María Arguedas», ibid., pp. 27-29.

Singularidades de José María Arguedas como escritor CARMEN ALEMANY BAY 


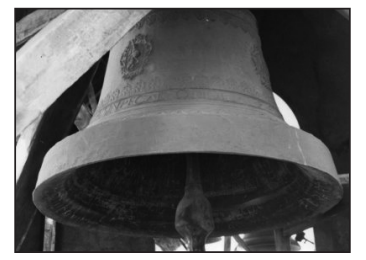

La campana María Angola.

6

Larco, op. cit., p. 22.

7

ld. En otra ocasión afirmó que "a medida que fui aprendiendo la literatura occidental, y leyendo los clásicos, especialmente españoles y rusos, decidí escribir, no con el propósito muy expreso de publicar, sino de desahogar mi estado de amargura, de descontento, casi de irritación contra esta descripción totalmente falsa que se hacía de la población indígena», en «La narrativa en el Perú contemporáneo», Rovira, José María Arguedas, op. cit., p. 43. El texto pertenece a una conferencia que Arguedas pronunció en un ciclo sobre narrativa latinoamericana actual organizado por la Casa de las Américas de Cuba del 16 de enero al 22 de febrero de 1968.

8

En «La narrativa en el Perú contemporáneo», op.cit., p. 43. En «Intervención de Arequipa» dirá a este respecto: "Yo comencé a escribir cuando leí las primeras narraciones sobre los indios, los describían de una forma tan falsa escritores a quien yo respeto, de quienes he recibido lecciones como López Albújar, como Ventura Calderón [...] En estos relatos estaba tan desfigurado el indio $y$ tan meloso $y$ tonto el paisaje o tan extraño que dije: No, yo lo tengo que escribir ta cual es, porque yo lo he gozado, yo lo he sufrido'», op. cit., 9.

Singularidades de José María Arguedas como escritor

CARMEN ALEMANY BAY de seguir escribiendo resultó apremiante decidió, el 28 de noviembre de 1969, que ese era el momento de poner punto y final a su vida: su existencia no tenía sentido si ésta no iba acompañada de la creación.

\section{Algunos datos sobre la formación literaria arguediana}

Pocos son los datos que tenemos sobre las lecturas que realizó José María Arguedas, tampoco él se prodigó en dejarnos demasiados testimonios en las entrevistas que concedió a lo largo de su vida, y ni siquiera su obra es transparente en este sentido. Seguramente, quien se creía no ser un escritor profesional, como confesó en El zorro de arriba y el zorro de abajo, se preocupó más por realizar lecturas orientadas a perfeccionar su creación, o a tomar posibles modelos para aquello que deseaba transmitir, que hacer una lectura sistemática de los referentes imprescindibles o canónicos de la literatura.

En verdad José María Arguedas no necesitó amarrarse a fuentes de las que abrevar posibles temas, ya que la propia experiencia vivencial y sus intensas investigaciones antropológicas y etnológicas eran materiales lo suficientemente sugerentes y penetrantes para configurar una obra de indudable originalidad. Desde nuestro punto de vista, lo que en realidad buscaba el narrador peruano en la obra de otros escritores es cómo poder representar con la mayor fidelidad su propia vida y, sobre todo, reflejar la complejidad del mundo andino. De ahí que la literatura oral quechua, como manifestó en una entrevista del año 1969, le sirvió desde sus primeras obras para encontrar un nuevo estilo. Ante la pregunta «¿Cómo empezó su relación con la literatura?» responderá: «Creo que al escuchar los cuentos quechuas que eran narrados por algunas mujeres y hombres que eran muy queridos en los pueblos de San Juan de Lucanas y Puquio, por la gracia con que cautivaban a los oyentes. Creo que influyó mucho la belleza de la letra de las canciones quechuas que aprendí durante la niñez»6.

Con esta base fundamental para sus escritos, muy tempranamente comprenderá que «los modelos de la literatura castellana no me servían para interpretar el mundo que anhelaba revelar» ${ }^{7}$. Ni los modelos de la literatura castellana, ni los de otras literaturas; pero no por ello dejará de sentir admiración en su juventud por autores peruanos $-\mathrm{y}$ seguimos con la respuesta del autor- como Manuel González Prada (1844-1918) y en especial su soneto «El amor». Otro poeta, José María Eguren (1874-1942), será uno de sus predilectos. Intuimos que esta afinidad con Eguren proviene de que el autor de Simbólicas supo reflejar en sus versos el espíritu de la costa peruana; pero este poeta simbolista también imprimió en sus versos una conciencia herida que tuvo su origen en la infancia y que no supo suturar a pesar del paso del tiempo, un caso sin duda comparable al de nuestro autor.

El libro Paisajes peruanos -compuesto entre 1912 y 1915 y dado a conocer fragmentariamente entre 1926 y 1941- de José de la Riva-Agüero (1885-1944) dejó probablemente alguna mella en la obra de Arguedas, específicamente en Los ríos profundos, ya que en aquella obra se describían con suntuosos detalles los paisajes desde Cuzco hasta Lima pasando por el río Apurímac y por Abancay. No sólo hay algunas identificaciones de los espacios sino que existen algunas pruebas que nos indican que conocía el mencionado texto porque fue citado en una ponencia que sobre la cultura mestiza en Ayacucho pronunció nuestro autor. Sin embargo, esta identificación ficcional no significaba que Arguedas compartiese los puntos de vista de quien él consideró un «hispanista» por defender un mestizaje en el que preponderaba la raíz hispánica, la cristiana y la occidental en detrimento de la quechua.

A quienes sí leerá con intensidad en los años universitarios será a Enrique López Albújar (1871-1966) y a Ventura García Calderón (1886-1959), autores que al igual que Arguedas describieron algunos usos y costumbres de las comunidades indígenas peruanas; aunque las posiciones que tomaron estos respecto al mundo indígena tampoco fueron del agrado de nuestro escritor. Son suyas expresiones como las siguientes: «Me sentí tan indignado, tan extrañado, tan defraudado que consideré que era imprescindible hacer un esfuerzo por describir al hombre andino tal como era y tal como yo lo había conocido a través de una convivencia muy directa» ${ }^{8}$. A pesar de las diferencias evidenciadas por nuestro autor, lo cierto es que la lectura de los mencionados escritores sirvió para dar un nuevo impulso a Arguedas en su intento de describir desde dentro y con 
fidelidad los valores que él había aprendido de su experiencia en contacto con los indígenas.

Será otro escritor peruano, César Vallejo (1892-1938), con el que Arguedas se sentirá plenamente identificado, pero no por sus impresionantes versos sino por la novela $E l$ tungsteno (1931) en la que el autor de Poemas bumanos denuncia la situación de abuso sobre el indígena en las minas peruanas. Asimismo, con el autor de Trilce compartirá lecturas: las obras de José Carlos Mariátegui (1894-1930) $y$, en la misma coordenada política, las de Lenin; ambos, pero sobre todo el primero, le sirvieron para adquirir una conciencia política y social, aunque el socialismo no mató en él lo mágico como se apresuró a afirmar.

Sin duda, otra de las lecturas continuadas serán las obras de Ciro Alegría (1909-1967), a quien le unía la misma devoción por el mundo indígena, aunque cada uno lo reflejase desde diferentes perspectivas. Obras como La serpiente de oro (1935), Los perros hambrientos (1939) y sobre todo El mundo es ancho y ajeno (1941) son referencias obligadas de la literatura peruana y también lo fueron para Arguedas: «lo que ocurre -como apuntó el autor de Los ríos profundos- es que en las novelas de Ciro Alegría aparece un indio que es tal desde el punto de vista social, pero no lo es desde el punto de vista cultural; entonces no tiene todas estas características, tan distintas, tan originales, como las del indio del sur» ${ }^{9}$. En cualquier caso, ambos pretendieron, a pesar de no ser maestros en técnicas narrativas, reflejar de manera fidedigna el mundo quechua con todas sus cargas espirituales y de una forma directa, diversa y múltiple ${ }^{10}$.

Siguiendo en el ámbito peruano, pero remontándonos unos siglos atrás, hay dos autores que tendrán una notable significación en su formación literaria: el Inca Garcilaso de la Vega (1539-1616) y Pedro Cieza de León (1520-1560). Del primero aprenderá la historia de su país y también el valor del mestizaje, encarnado en la vida y obra de este autor, pero sobre todo el intento de Garcilaso de imitar el lenguaje de la vida real, los sonidos propios de la lengua y algunas alteraciones fonéticas de determinadas regiones del Perú. De Cieza de León, mencionado en el discurso de entrega del Premio Inca Garcilaso, le deslumbraron las descripciones que este español, historiador del Perú, realizó en sus escritos: «ninguna descripción del Perú nos parece más hermosa ni más exacta que la que hace Pedro Cieza de León» ${ }^{11}$.

Fuera ya de su país, pero sin salirnos del ámbito latinoamericano, nuestro autor confiesa que Don Segundo Sombra (1926), del argentino Ricardo Güiraldes (1886-1927), será otra de las lecturas que le «alumbraron el camino». Seguramente porque esta obra define la esencialidad de las raíces argentinas, porque recoge las costumbres de la pampa y la sabiduría popular de los gauchos y fundamentalmente porque Güiraldes está describiendo el final de una época y también de una forma de vida en la pampa. Y precisamente, esta misma intencionalidad es la que intuimos en los escritos arguedianos: preservar culturalmente lo que se sabe que con la marcha de los tiempos está condenado a desaparecer.

Otros escritores más coetáneos serán también referentes del escritor. Admirará a Juan Rulfo (1918-1986) por su personalidad y porque en su obra describió la entraña misma de lo mexicano, otra realidad ajena a las tribulaciones de la Ciudad de México. A este autor le dedicará párrafos afectuosos en el «Primer diario» de El zorro de arriba y el zorro de abajo y con anterioridad, en el año 1960 , escribió un efusivo comentario sobre Pedro Páramo ${ }^{12}$. También recordará en el citado diario al uruguayo Juan Carlos Onetti (19091994) con especial simpatía, y al colombiano Gabriel García Márquez (1928) lo comparará, por su forma de contar historias, con doña Carmen Taripha, vecina del pueblo de Maranganí (Cuzco). Lo que Arguedas destacará de la obra de los escritores antes mencionados, como también de la del brasileño Joao Guimarâes Rosa (1908-1967), es que ellos, al igual que él, escriben por pasión literaria.

Menos simpatías le reportarán la obra de Alejo Carpentier (1904-1980), la de José Lezama Lima (1910-1976), la de Carlos Fuentes (1928) y, sobre todo, la de Julio Cortázar (1914-1984), con quien mantuvo una ardua polémica ${ }^{13}$. A todos ellos les recriminará ser escritores profesionales y tener como único mérito el aplicar «una técnica que se ha aprendido y se ejerce específicamente, orondamente, para ganar plata».

Fuera ya de la literatura latinoamericana confesará en diversas entrevistas que leyó con gusto a algunos novelistas franceses y rusos; entre los primeros destacará a Víctor Hugo (1802-1885) y específicamente dos de sus obras, Los miserables (1862) y sobre to-
9

En «La narrativa en el Perú contemporáneo», op. cit., p. 43.

10

Véase, ibid., p. 46

11

José María Arguedas, "La sierra en el proceso de la cultura peruana», en Formación de una cultura nacional indoamericana (prólogo de Ángel Rama), México, Siglo XXI, 1975, p. 9.

12

En el suplemento dominical del periódico limeño El Comercio, José María Arguedas publicó el 8 de mayo de 1960 una elogiosa reflexión sobre Juan Rulfo titulada "Reflexiones peruanas sobre un narrador mexicano (Juan Rulfo)».

13

De esta manera expresa Arguedas sus querencias y desavenencias con los escritores citados: "A Onetti lo vi en México. Andaba con bastón, atendido por algunos que le conocían. Yo no había leído nada de él. Lástima. Le hubiera saludado: a don Alejo [Carpentier] no me atreví a acercarme, me lo presentaron dos veces. Dicen que es tímido, pero sentía, o lo sentía como a un europeo muy ilustre que hablaba castellano. Muy ilustre, de esos ilustres que aprecian lo indígena americano, medidamente [...] Carlos Fuentes es mucho artificio, como sus ademanes. De Cortázar sólo he leído cuentos. Me asustaron las instrucciones que pone para leer Rayuela. Quedé, pues, merecidamente eliminado, por el momento, de entrar en ese palacio», en José María Arguedas, El zorro de arriba y el zorro de abajo, Buenos Aires, Losada, 1971, pp. 17-18. De Fuentes dirá más adelante: "¡Ah! La última vez que vi a Carlos Fuentes, lo encontré escribiendo como a un albañil que trabaja a destajo. Tenía que entregar la novela a plazo fijo. Almorzando, rápido, en su casa. Él tenía que volver a la máquina», p. 26.

Singularidades de José María Arguedas como escritor CARMEN ALEMANY BAY 
14

Véase, «Introducción» a Los ríos profundos (edición de Ricardo González Vigil), Madrid, Cátedra, 1998, pp. 89-91.

15

Una visión más extensa sobre este aspecto puede verse en Carmen Alemany Bay, "José María Arguedas y su acercamiento a lo español a través de la antropología, la etnología y la literatura», Relaciones entre la literatura española e hispanoamericana en el siglo XX. América sin nombre, 3 (2002), pp. 5-13.

16

Puede verse la relación de artículos que sobre este tema publicó el autor en Carmen Alemany Bay, "Bibliografía de y sobre José María Arguedas», en Rovira, José María Arguedas. Una recuperación indigenista pp. 136-137.

Singularidades de José María Arguedas como escritor

CARMEN ALEMANY BAY do Los trabajadores del mar (1866); y entre los rusos a Fedor Dostoievsky y su obra $E l$ sepulcro de los vivos. Mención mucho más general tendrán otros escritores que sin duda pertenecen al ámbito de la universalidad: Sófocles, William Shakespeare, Edgar Allan Poe, Herman Melville, Arthur Rimbaud, Walt Whitman, Tomas S. Eliot, Brecht o Albert Camus; entre los españoles citará a Francisco de Quevedo y recordará El Quijote en su novela El Sexto.

Tampoco se nos escapa su lectura de algunas obras de William Faulkner (1897-1962), autor decisivo para los escritores del boom, y fundamentalmente Las palmeras salvajes (1939), novela decisiva para la configuración de Los ríos profundos. El entusiasmo por esta obra quedó manifiesto en una carta que envió a Manuel Moreno Jimeno el 4 de abril de 1941 donde, por otra parte, admite su ignorancia de la «literatura americana» ${ }^{14}$.

Si algún sentido tiene elaborar el elenco de escritores destacados por el propio José María Arguedas, es por las posibles conclusiones que de éstas pueden derivarse. Desde nuestro punto de vista, intentó sacar de cada una de estas lecturas una experiencia abocada a extraer aquello que le sirviese para contar su mundo desde adentro; de ahí que sea fundamental la lectura de autores universales y también de escritores latinoamericanos que como él intentaron acercarse a un mundo similar al suyo, a los que entienden la literatura como necesidad y no como profesionalidad.

\section{La antropología y etnología en la narrativa $\operatorname{arguedian}^{15}$}

La verdadera fuerza de la narrativa de José María Arguedas, en cualquier caso, no nace de sus conocimientos literarios sino de la utilización que él hace de sus estudios etnológicos y antropológicos, así como de la aplicación de estos a su narrativa. Desde nuestro punto de vista, aquello debe ser considerado como una originalidad y no como una diferenciación marginal. Sus estudios y publicaciones en este campo $^{16}$ siguen siendo hoy en día referentes, y es que el autor de Los ríos profundos estuvo siempre al tanto de los avances de estas disciplinas. Asimismo, estas investigaciones, que formarán parte de su trabajo como docente y como investigador, concurrirán en un mismo fin: el conocimiento de la cultura quechua y la voluntad de transmitirlos a la literatura, transformándolos en materia ficcional.

Por lo dicho hasta estos momentos, se intuye que la tarea de investigación antropológica y etnológica ocupó gran parte de su vida, pero fue entre 1953 y 1963 el período en el que se concentran la mayoría de sus publicaciones en este campo, ya que en las citadas fechas ocupó el cargo de Jefe del Instituto de Estudios Etnológicos del Museo de Cultura.

De entre todas las investigaciones antropológicas y etnológicas queremos señalar su libro Las comunidades de España y del Perú (1968), un trabajo por el que se recibió como doctor en Etnología en 1963 por la Universidad de San Marcos de Lima. Se trata de un estudio comparativo entre dos pueblos agrícolas de la región de Zamora pertenecientes al partido judicial de Sayago, Bermillo y La Muga, y algunas regiones del Perú andino. La investigación fue realizada en 1958, y las poblaciones citadas fueron elegidas por el peruano por ser pueblos aislados y con un acusado retraso social respecto a otras comunidades españolas. José María Arguedas quedó sorprendido por las múltiples semejanzas entre estas y las poblaciones de la sierra peruana.

$\mathrm{Su}$ experiencia en tierras españolas y sus investigaciones en esta zona tendrán al menos dos aspectos reseñables. En su estadía en España conoció y le entusiasmaron dos ensayos de Joaquín Costa citados con frecuencia en Las comunidades de España y del Perú, nos referimos a Colectivismo agrario y a Derecho consuetudinario. Es curioso que un neoindigenista como José María Arguedas lea con profundidad a un krausista como Joaquín Costa, tal como lo hiciera años antes en España otro narrador, el indigenista boliviano Alcides Arguedas, quien compartió las ideas krausistas españolas y las consideró como modelo para solucionar el problema indígena en su país. Por otro lado, y este aspecto sí fue muy decisivo para su pensamiento y su obra, se dio cuenta de que el futuro, y también el pasado, de los pueblos andinos tienen que tener indispensablemente en cuenta $-\mathrm{y}$ no siempre de forma negativa- el referente español, idea que plasmó de forma definitiva en Los ríos profundos que fue publicada en el mismo año de su estancia en España.

Las novelas y cuentos de José María Arguedas, a medida que van avanzando sus conocimientos sobre la cultura española -gracias, insistimos, a sus estudios de antropo- 
logía y etnología- evolucionarán hacia la convicción de que la fusión de culturas es imprescindible para entender el pasado del Perú, pero también para construir un sólido futuro exento de aculturación. Es por ello que la obra arguediana, que empezó con marcadas diferencias entre las culturas que integran el Perú, pasará por un proceso de necesaria integración y, tras esa aceptación, sus ficciones derivarán hacia los profundos cambios de su país en los años sesenta.

\section{La búsqueda de un lenguaje singular}

Si la formación literaria de José María Arguedas lo dota de originalidad, así como la integración de elementos antropológicos y culturales a sus textos, de trascendente podríamos calificar la búsqueda de un lenguaje singular que sin duda sorprende a cualquier lector que se acerque a sus obras. No es extraño por tanto que la crítica haya insistido en este aspecto de la obra arguediana. Los trabajos de Alberto Tauro, Sebastián Salazar Bondy, Edmundo Bendezú, Juana Martínez y, sobre todo, Alberto Escobar, William Rowe y José Antonio Rodríguez Garrido nos señalan la importancia del intento de quechuización del español que intentó José María Arguedas y sus repercusiones en la literatura latinoamericana como valor de modernización. Este aprovechamiento literario de su condición de bilingüe será, según Ángel Rama, la empresa «más difícil que ha intentado un novelista en América» ${ }^{17}$.

El conocimiento del quechua antes que del castellano ( $«$ mi lengua predominante era el quechua. Hasta los nueve años hablaba muy poco español y dominaba el quechua»), capacitó excepcionalmente a nuestro autor para crear una lengua en la que se estableciese una íntima relación entre la experiencia y el lenguaje, buscando siempre la armonía entre las dos lenguas y que el resultado fuese, en la medida de lo posible, un lenguaje unívoco y universal. Esta experimentación y este atrevimiento verbal suponen la sacralización del lenguaje y sacar a éste de su uso normal, no sólo para expresar a través de la escritura el pensamiento y las costumbres quechuas, sino desde el convencimiento de que se le está dando a la literatura una nueva vida. Con esta proeza lingüística Arguedas consiguió la creación de un lenguaje y un universo litera- rios que al menos en el lenguaje español o se desconocía o se había olvidado.

El convencimiento de que la fusión de ambas lenguas, aunque con predominio del castellano, era una forma legítima de explicar la realidad del mundo andino fue expresado sin paliativos en un artículo del año 1939, «Entre el kechwa y el español». En esas páginas destacó que el primero era un idioma «sin prestancia y sin valor universal» para la literatura, y que por ello el mejor camino era la construcción de una lengua literaria mixta, hecha fundamentalmente de habla española pero con sintaxis, palabras y frases provenientes del quechua; en palabras de Arguedas, «encontrar los sutiles desordenamientos que harían del castellano el molde justo, el instrumento adecuado» ${ }^{18}$.

Si estos son los objetivos ${ }^{19}$, necesario es aclarar los procedimientos. Ya se han señalado algunos, pero cabría insistir en la alteración del orden lógico de la frase por la dislocada sintaxis y el reiterado empleo del gerundio que frena el ritmo temporal creando la sensación de lentitud; asimismo, se favorece cierta ambigüedad en la concordancia de las palabras y se incluyen vocablos quechuas en el interior de los textos. Para que aquellos sean traducibles por el lector, Arguedas utiliza varios recursos que van desde la introducción de palabras o frases en quechua, y a continuación la traducción al español; hasta la explicación semántica del término quechua y a partir de ésta la introducción de descripciones que en ocasiones nos remiten a su labor como etnólogo; el caso más paradigmático es el comienzo del capítulo VI de Los ríos profundos. El resultado es lo que Juana Martínez ha denominado la «transcripción simultánea»al español de las palabras quechuas: se interviene en quechua pero la voz se deja oír en español. De esta forma no hay dificultad para comprender el texto y el lector acaba aceptando estas transformaciones de forma natural ${ }^{20}$.

Esta lengua ficticia, artificial, nos puede dar impresión de realidad; pero no debemos caer en el engaño, ya que se trata de un recurso lingüístico en el que José María Arguedas buscó la forma de trasmitir su cultura principal, la quechua. No sólo ésta fue su intención, sino que pretendió que su visión del mundo fuese conocida como una realidad más de ese complejo mundo que es América Latina.
17

Ángel Rama, "Diez problemas para el novelista latinoamericano», Casa de las Américas, 26 (octubre-noviembre de 1964), p. 22.

18

Este proceso de asimilación y de catadura de nuevos lenguajes se irá configurando, fundamentalmente, a través de dos etapas si seguimos lo dicho por William Rowe en Mito e ideología en la obra de José María Argue das, Lima, Instituto Nacional de Cultura, 1979, pp. 61-63. En la primera, en la que se incluirían los cuentos de Agua y su novela Yawar Fiesta, Arguedas intentó una mezcla lingüística del español y del quechua, aunque desde el punto de vista cultural predominase la cultura indígena. En la segunda, a partir de Diamantes y pedernales y de manera plena en Los ríos profundos, Arguedas optó por introducir mecanismos más sutiles en ese intento de quechuización de la lengua castellana. Estos se resumirían, según el citado crítico, en la variación del orden gramatical y en un orden especial de las palabras que aparecen determinados por el continuo uso del asíndeton y de las repeticiones.

19

Según Antonio Cornejo Polar, la búsqueda de ese nuevo lenguaje se proyectaría hacia dos metas. Por una parte, que el lenguaje tenga la capacidad de mencionar las dimensiones inéditas del hombre y del mundo, es decir, revelar lo que aún no se ha revelado: la intimidad del mundo indio; y otra, que esta revelación no se limite a la expresión sino que se resuelva en comunicación, en «El sentido de la narrativa de Arguedas», Revista Peruana de Cultura, 13-14 (diciembre de 1970), p. 40.

20

Juana Martínez, "Acerca de Los ríos profundos y José María Arguedas», en José María Arguedas, Los ríos profundos (edición de Juana Martínez), Madrid Anaya \& Mario Muchnik, 1995, p. 311 .

Singularidades de José María Arguedas como escritor CARMEN ALEMANY BAY 
21

El autor afirmó en "La narrativa en el Perú contemporáneo» que «en este pequeño libro de relatos están descritos dos elementos del mundo andino: el odio y la ternura. El odio, odia, odia con todas sus fuerzas a los que lo explotan y a los que lo odian a su vez, pero hay un hecho que es muy importante: en los indios el odio no es más grande que la ternura, porque entre ellos se aman intensamente, $y$ esto hace que el odio sea verdaderamente un odio de tipo fecundo y no un odio perturbador», op. cit., p. 43.

22

Antonio Cornejo Polar, «Un ensayo sobre 'los zorros' de Arguedas», en José María Arguedas, El zorro de arriba y el zorro de abajo (edición crítica de Eve-Marie Fell), Madrid CSIC, Colección Archivos, 1990, p. 297.

23

Rita Gnutzmann, Novela y cuento del siglo $X X$ en el Perú, Alicante, Cuadernos de América sin nombre, 2007, p. 85. Ello no es óbice, como sigue apuntando Gnutzmann, para que "el capítulo II, 'El despojo', se convierta en un verdadero ensayo sociológico sobre el abuso (robos de los mistis, rebelión de los indios y el consiguiente escarmiento". Y como se advierte a pie de página, en la novela "existe una auténtica estratificación y amplificación social: mistis (principales y menos principales), comuneros (indios de ayllus $y$, los inferiores, punarunas y los concertados), además los «chalos», emigrantes aculturados venidos de Lima con ideas socialistas (mariateguianas). Pero también se distinguen los «mistis» socio-culturalmente: el tradicionalista don Julián, influido por la cultura indígena frente a los terratenientes modernos unidos al poder $y$ al dinero exteriores a la sierra».

24

Algunos de los argumentos expuestos en la explicación de Los ríos profundos proceden del artículo escrito en colaboración con José Carlos Rovira y titulado "Sobre algunas visiones de lo español y una perspectiva indigenista», en Actes du Colloque Almoreal. Espagnols et Hispano-Américains des XIXo et $X X^{\circ}$ siécles: représentations réciproques, Le Mans, Université du Maine, 1990; específicamente las pp. 103-105.

Singularidades de José María Arguedas como escritor

CARMEN ALEMANY BAY

\section{Las ficciones de José María Arguedas}

Como ya hemos señalado, José María Arguedas, a través de sus novelas y relatos, se convirtió en un intérprete del mundo andino en sus primeras obras y, poco a poco, su punto de mira se fue ampliando al integrar en este proceso literario su visión sobre lo español con el fin de explicar su país a través de la fusión de culturas. En sus últimas obras, en cambio, nos ofrecerá una visión integral del Perú, y en todo este proceso serán fundamentales los aportes de cada una de las singularidades que hemos señalado con anterioridad.

Con la publicación de su primer libro de cuentos, Agua, el autor va desgranando un universo, el andino, en donde muestra claramente una posición política a través de la descripción de la vida en el pueblecito de San Juan de Lucanas. En apariencia, poca originalidad encontramos en estos tres cuentos de factura cuantitativamente asimétrica, sin embargo, concurren algunos rasgos que marcarán su obra posterior y que serán identificativos de su producción literaria ${ }^{21}$. Entre ellos, la inclusión de un protagonista infantil, blanco, que vive en la sierra peruana $y$, como ha señalado Antonio Cornejo Polar, será a partir de estos cuentos cuando se diseñe la personalidad cultural de Arguedas como personaje ${ }^{22}$. De manera específica, uno de los cuentos de Agna, "Warma kuyay»-que previsiblemente fue escrito antes de «Los escoleros» y del que da título al libro-, podríamos considerarlo como precedente de su novela Yawar Fiesta. Además, el autor describe en las páginas de este relato algunos juegos indígenas propios de la sierra peruana, lo que supone la inclusión de observaciones que nacen de su labor como antropólogo y que pasará a ser una constante en títulos posteriores. No debemos olvidar, por otra parte, que la fusión de ficción y antropología era inédita en la novela indigenista.

Su primera novela, Yawar Fiesta, supone una superación del esquema indigenista, ya que la lucha entre los dos poderes no se centra en lo social, sino en la reivindicación cultural $^{23}$. Pero podríamos añadir algo más, Arguedas se aleja en esta entrega de los conflictos socioeconómicos presentes en la novela indigenista y opta por incorporar un planteamiento de índole telúrica que ayuda a que la presencia de lo español sea mucho más natural y que pase a ser un ingrediente más de la visión de su mundo.

Será en Los ríos profundos ${ }^{24}$ cuando José María Arguedas logre la plena integración de ambas culturas: la española y la quechua. A partir de una serie de imágenes que el autor incluye en el primer capítulo podemos llegar a la conclusión de que Arguedas aboga por un Perú mestizo, fuertemente cargado de herencia indígena, pero también con presencia de lo hispánico: el muro incaico y la María Angola, el Viejo y el adolescente Ernesto, el pongo y el Cristo de la Catedral, o la Catedral y la alegría de los ríos. No sólo los espacios son decisivos, también el lenguaje a través de la fusión del español y el quechua. Como el mismo autor subrayó, en Los ríos profundos halló «los sutiles desordenamientos» que hacían del castellano «el molde justo, el instrumento adecuado» para conseguir sus propósitos: acercar al lector no familiarizado con el mundo andino a las cosas que él vivió y conoció en profundidad.

El niño Ernesto nos describirá en las primeras páginas de la novela la sensación de vida que transmite el muro inca, y frente a esa emoción encontramos otras sensaciones, ahora de sufrimiento y de tristeza, que transmite el sonido de la campana de la catedral, la «María Angola». Su sonido, lleno de poder trasformador y de una significación muy especial para los cuzqueños, se oye en los grandes lagos donde «a su canto triste -nos dice el narrador- salen del agua toros de fuego, o de oro, arrastrando cadenas» (p. 17). Estos toros -símbolo español- serían antiguas serpientes -amarus- convertidas por «María Angola»: «Pensé que esas campanas debían ser illas, reflejos de la María Angola, que convertiría a los amarus en toros. Desde el centro del mundo la voz de la campana, hundiéndose en los lagos, habría transformado a las antiguas criaturas» (p. 17). No será la primera ni la última vez que José María Arguedas haga referencia a los amarus, en un artículo publicado en Cultura y Pueblo los define de la siguiente manera: «Antiguo dios, el Amaru, que tenía forma de serpiente y vivía en el fondo de los lagos, fue trasformado en toro, según las creencias indígenas». Una mutación en la que un símbolo propiamente incaico se ha transculturado en un símbolo español.

No menos significación tendrá la catedral, construida, como dice el padre de Ernesto en la novela, por «el español, con la piedra 
incaica y las manos de los indios»; mestizaje entre lo indio y lo español o un sincretismo cristiano con aporte andino. Y aquí podríamos sacar nuevamente a colación otro texto en el que Arguedas relaciona la ficción con la investigación. Nos referimos a «El nuevo sentido histórico del Cuzco», reproducido en Indios, mestizos y señores, y en donde el autor reflexiona sobre el sincretismo de algunas construcciones cuzqueñas como la catedral:

[los españoles] no pudieron o no quisieron derruir los cimientos de algunos templos o residencias; sin sospechar que esto también llegaría a ser un símbolo y una imagen del futuro mundo peruano. [...] En los siglos duros y brutales de la Colonia germinó un nuevo Perú que hoy parece muy próximo a su definición. El pueblo español llegó para fecundar el Nuevo Mundo, no sólo para conquistarlo ${ }^{25}$.

Y el niño Ernesto sale del Cuzco entre las imágenes de la tristeza que auditivamente le ha trasmitido la campana, o visualmente el Cristo arguediano. Pero esta imagen del Crucificado sintoniza con la visión que del indio tiene Arguedas, y así lo dejó explicitado en «El valor poético y documental de los himnos religiosos quechuas», incluido en Indios, mestizos y señores, o en el culto del indio a la cruz («La fiesta de la Cruz») perteneciente al citado libro.

En definitiva, como apuntó el autor en «La sierra en el proceso de la cultura peruana», cuando una cultura es invadida por otra, pero la sometida tiene una profunda historia «el sometimiento al estado de servidumbre no la destruye, se produce un inevitable estado de intercambio, de mestizaje con la cultura invasora ${ }^{26}$. No sólo eso queda plasmado en Los ríos profundos, José María Arguedas ha logrado además introducir en su justa medida todo aquello por lo que venía luchando desde hacía años: un lenguaje preciso, la fusión de la literatura y la antropología, la interacción de dos culturas, la lucha de los indígenas representadas por las chicheras y la revelación del espacio autobiográfico de su niñez y juventud.

$\mathrm{Su}$ siguiente novela, Todas las sangres, supone otro intento de superación narrativa centrado fundamentalmente en el mensaje, ya que intenta ofrecernos una visión totalizadora de la situación social, política, cultural y económica de Perú mediante un diseño ficcional en el que se entremezclan la realidad y la utopía. La diferencia insalvable que entre los indios y los blancos aparecía en sus primeros escritos se convierte en esta novela en un mestizaje casi ideal que podría vislumbrarse como posible solución al galopante proceso de aculturación que según el autor estaba sufriendo su país.

De diferente talante será su última ficción, publicada póstumamente, El zorro de arriba y el zorro de abajo. La novela se desarrolla en el costeño puerto de Chimbote, paradigma del nuevo Perú y a su vez un universo degradado por las constantes transformaciones industriales que han traído consigo la desintegración social y cultural de los indios y de los sectores marginados. Este hilo argumentativo se entremezcla con cuatro diarios y un epílogo autobiográficos e insiste sobre todo en la imposibilidad de seguir escribiendo y, como consecuencia, el incansable deseo de poner fin a su vida. Los citados fragmentos se fusionan con otro relato, una leyenda indígena que fue escrita en quechua y que da título al libro.

El autor de Los ríos profundos, quizá a esas alturas, al borde del suicidio, fue consciente de las dificultades reales de llevar a cabo un mestizaje auténtico, sin aculturación, máxime cuando otras fuerzas imperiosas e imperialistas estaban rearticulando la idiosincrasia del país. A pesar de ello, en su discurso de entrega del Premio Inca Garcilaso, que fue incluido en El zorro de arriba y el zorro de abajo, insistirá en la integración de las dos culturas principales del Perú, la de la sierra y la de la costa, y también en otra de orden superior, la quechua y la española; pero más allá de todo ello: «Contagiado para siempre de los cantos y los mitos, llevado por la fortuna hasta la Universidad de San Marcos, hablando por vida el quechua, bien incorporado al mundo de los cercadores, visitante feliz de grandes ciudades extranjeras, intenté convertir en lenguaje escrito lo que era como individuo» ${ }^{27}$.
José María Arguedas, Indios, mestizos y señores (compilación e introducción de Sybila Arredondo de Arguedas), Lima, Horizonte, 1985.

26

Véase, Martínez, op. cit., p 301.

27

José María Arguedas, "No soy un aculturado»; palabras pronunciadas en el acto de entrega del Premio Inca Garcilaso. Tomamos la referencia de Rovira, José María Arguedas, op. cit., p. 40 .

Singularidades de José María Arguedas como escritor

CARMEN ALEMANY BAY 